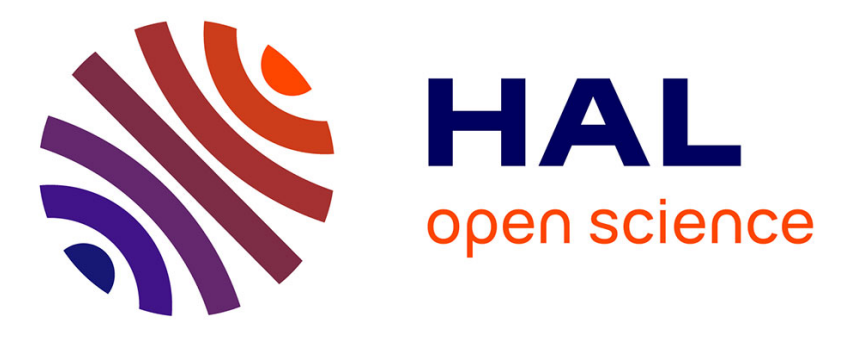

\title{
Lemniscular [16]Cycloparaphenylene A Radially Conjugated Figure-Eight Aromatic Molecule
}

Kabali Senthilkumar, Mateusz Kondratowicz, Tadeusz Lis, Piotr J

Chmielewski, Joanna Cybińska, José L Zafra, Juan Casado, Thomas Vives, Jeanne Crassous, Ludovic Favereau, et al.

\section{To cite this version:}

Kabali Senthilkumar, Mateusz Kondratowicz, Tadeusz Lis, Piotr J Chmielewski, Joanna Cybińska, et al.. Lemniscular [16]Cycloparaphenylene A Radially Conjugated Figure-Eight Aromatic Molecule. Journal of the American Chemical Society, 2019, 141 (18), pp.7421-7427. 10.1021/jacs.9b01797 . hal-02120740

\section{HAL Id: hal-02120740 \\ https://hal-univ-rennes1.archives-ouvertes.fr/hal-02120740}

Submitted on 21 Jun 2019

HAL is a multi-disciplinary open access archive for the deposit and dissemination of scientific research documents, whether they are published or not. The documents may come from teaching and research institutions in France or abroad, or from public or private research centers.
L'archive ouverte pluridisciplinaire HAL, est destinée au dépôt et à la diffusion de documents scientifiques de niveau recherche, publiés ou non, émanant des établissements d'enseignement et de recherche français ou étrangers, des laboratoires publics ou privés. 


\section{INTRODUCTION}

The topology and distortion of a cyclic $\pi$-electron system have a fundamental influence on its properties. In the most common case, found e.g. in benzene, the $\pi$ conjugated framework, consisting of an array of $\mathrm{sp}^{2}$ hybridized centers, has a planar structure with the constituent $p_{z}$ orbitals in perfectly parallel alignment (Figure 1A). By gradual distortion of such $\pi$ systems, it is possible to produce molecules with radial (in-plane) conjugation, in which the $p_{z}$ orbitals are perpendicular to a cylindrical surface (Figure 1B). This type of conjugation is found in various tubular aromatics, notably $[n]$ cycloparaphenylenes ([n]CPPs), ${ }^{1-5}$ carbon nanobelts, ${ }^{6,7}$ and nanotube endcaps. ${ }^{8,9}$ Planar and radial aromatics can be represented respectively by an annulus and an open cylinder, which are topologically equivalent. Since these surfaces are orientable, the corresponding $\pi$ systems follow the Hückel aromaticity rules in the ground state. ${ }^{10}$ Radial $\pi$ conjugation is therefore fundamentally related to planar $\pi$ conjugation and has indeed been shown to sustain macrocyclic (global) Hückel aromaticity in charged $[n]$ CPP rings. ${ }^{11-13}$ When the $\pi$ system is twisted along the perimeter, its topology is altered, resulting in the increase of the so-called linking number. The latter parameter, denoted $L k$, is expressed in units of $\pi$ (i.e. $180^{\circ}$ ) and corresponds to the number of half-twists introduced into the aromatic surface. ${ }^{14-16}$ Such twisted aromatics alternate between ground-state Hückel and Möbius aromaticities, for even and odd $L k$ values, respectively. ${ }^{15,17,18}$ Among these systems, molecules with $L k=1^{15,17-22}$ and $L k=3,23,24$ have aroused particular interest since the first example of a Möbius-aromatic hydrocarbon was reported in 2003 by Herges et al.
A planar, $L k=0$

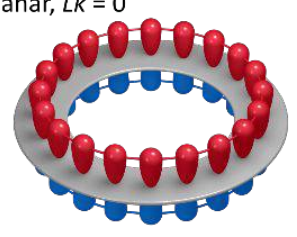

C planar, $L k=2$

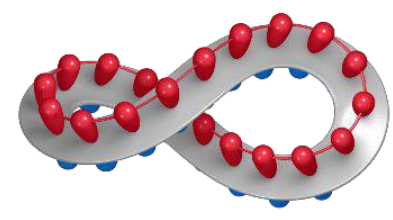

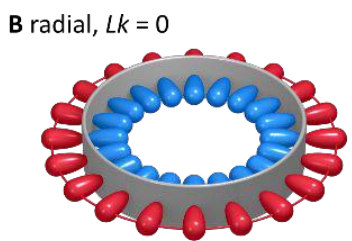

D radial, $L k=2$ (this work)

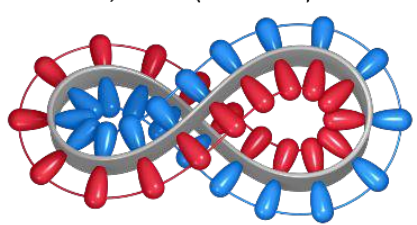


Figure 1. $\pi$-Conjugated systems with different combinations of twist and local curvature. The blue and red lobes represent $\mathrm{p}_{z}$ orbitals of $\mathrm{sp}^{2}$-hybridized atoms, without implying the actual geometry of the $\pi$-bonded framework.

Surfaces with $L k=2$ have two edges that are interlocked in space. Aromatic molecules with this topology adopt figure-eight (lemniscular) shapes, which help maximize $p$ orbital overlap and reduce internal strain. Lemniscular aromatics reported to date, mostly porphyrinoids ${ }^{15,18}$ and some rare carbocyclic frameworks, ${ }^{25,26}$ have been invariably characterized by locally planar $\pi$-conjugation (Figure 1C). Combining twist and in-plane conjugation in lemniscular aromatics (Figure 1D) may provide fundamental insight into the intricate relationship between three-dimensional structure and $\pi$-electron conjugation. This task is however challenging because of the unfavorable strain of such constructs, which requires an effective structural design and needs to be introduced by appropriate synthetic methodology. ${ }^{27}$ Here we show that it is possible to combine radial conjugation with a double twist of the $\pi$ surface in an appropriately bridged [16]CPP derivative. The resulting system adopts a chiral lemniscular shape while retaining a contiguously conjugated macrocyclic circuit.

\section{RESULTS AND DISCUSSION}

Synthesis. The target cycloparaphenylene lemniscate $(C P P L, \quad 1)$, was obtained from 9,9'-bicarbazole tetraboronate $\mathbf{3}$ and Jasti's $\mathrm{U}$-shaped building block $\mathbf{4}^{1}$ in a concise three-step synthesis (Scheme 1). Carbazole-2,7diyl building blocks have been previously incorporated into nanohoop structures, to produce rigidified yet circularly shaped CPP derivatives.9,28 The octamethoxy intermediate 6, obtained using the Yamamoto coupling in a double macrocyclization step, was structurally characterized and found to possess the requisite figure-of eight structure, albeit with incomplete $\pi$ conjugation (Scheme 1). The macrocyclic loops in 6 are relatively unstrained, as evidenced by the nearly planar geometries of all benzene rings. Reductive aromatization of the four masked $p$-phenylene units in $\mathbf{6}$ was performed using the method reported by the Yamago group. ${ }^{29}$ Under these conditions, $\mathbf{6}$ was cleanly converted into the CPPL product $\mathbf{1}$, which was isolated in an $85 \%$ yield as a yellowish powder.
Scheme 1. Synthesis of the [16]cycloparaphenylene lemniscate (CPPL, 1), ${ }^{a-c}$ and the structure of bicarbazole intermediates. ${ }^{d}$
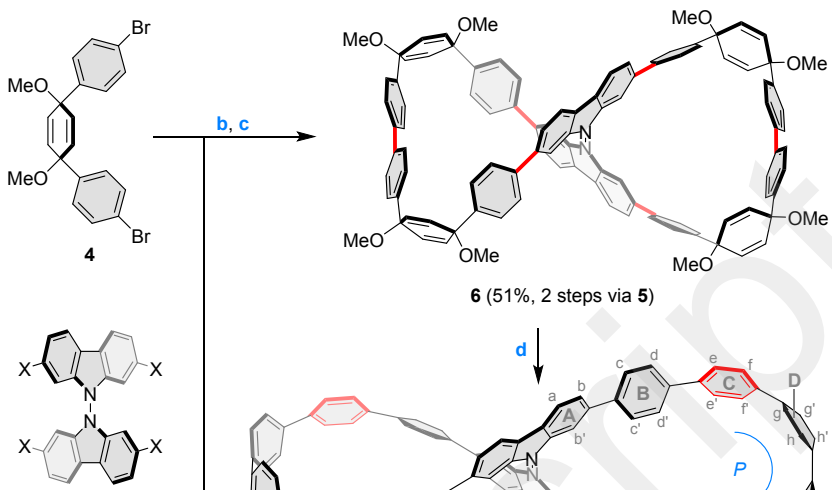

a $2(X=B r)$

$\rightarrow 3(X=$ Bpin, $99 \%)$
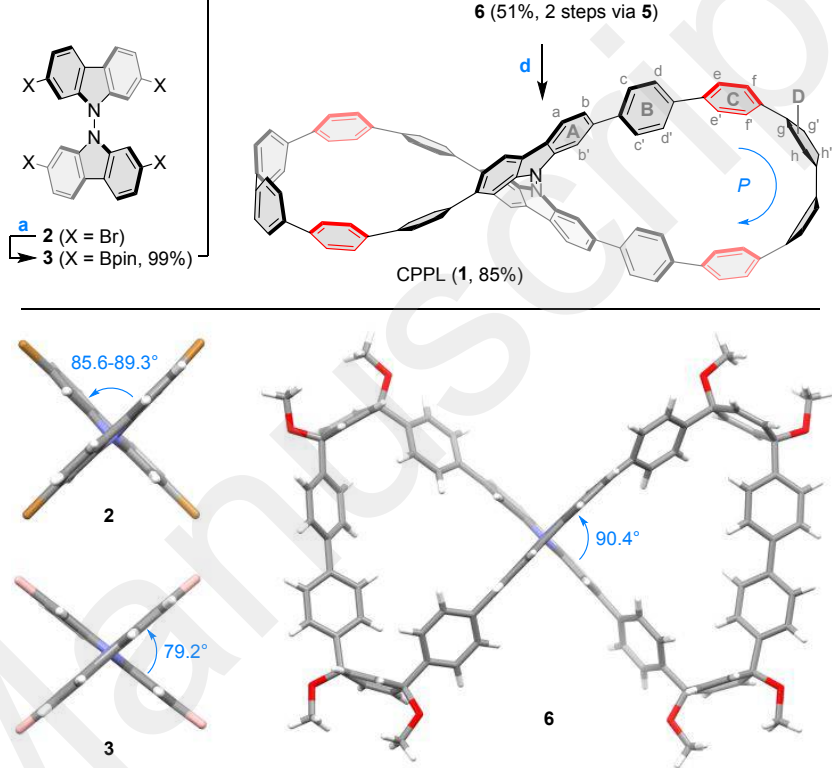

${ }^{a}$ Reagents and conditions: (a) $\mathrm{B}_{2}(\mathrm{Pin})_{2}, \mathrm{PdCl}_{2}(\mathrm{dppf}), \mathrm{KOAC}$, 1,4-dioxane, $110{ }^{\circ} \mathrm{C}$, overnight; (b) $\mathrm{Pd}(\mathrm{OAc})_{2}$, dppf, $\mathrm{Ag}_{2} \mathrm{O}$, $\mathrm{K}_{2} \mathrm{CO}_{3}$, toluene, $\mathrm{MW}, 85^{\circ} \mathrm{C}, 2 \mathrm{~h}$; (c) $\mathrm{Ni}(\mathrm{COD})_{2}$, bpy, $\mathrm{THF}, \mathrm{DMF}$, $\mathrm{MW}, 85^{\circ} \mathrm{C}, 2 \mathrm{hr}$; (d) $\mathrm{H}_{2} \mathrm{SnCl}_{4}, \mathrm{THF}, \mathrm{RT}, 3 \mathrm{~h}$. ${ }^{b}$ The structure of $\mathbf{5}$ is given the Supporting Information. ${ }^{c}$ The $(P)$ enantiomer is shown for $1{ }^{d}$ Solid-state geometries; solvent molecules and disordered groups (including pinacol rings in $\mathbf{3}$ ) are omitted for clarity.

Molecular Structure and Dynamics. The structure of CPPL was unambiguously determined using one- and two-dimensional NMR spectroscopy, mass spectrometry, and a range of optical methods, with additional support of theoretical calculations. The lowest-energy $D_{2}$ symmetrical conformer of $\mathbf{1}$ found in the gas phase using density functional theory (DFT) is shown in Figure 2. Variable-temperature ${ }^{1} \mathrm{H}$ NMR spectra of $\mathbf{1}$, analyzed with the aid of correlation methods, are consistent with such a figure-eight structure possessing internal degrees of freedom (Figure 3 and Supporting Information). At $300 \mathrm{~K}$ in dichloromethane- $d_{2}$, the spectrum contains a unique $A B C D$ spin system ( $g g^{\prime}$ 'hh'), which indicates that the macrocycle is indeed twisted and that the corresponding phenylene rings ( $D$, cf. Scheme 1 ) do not rotate within the oligophenylene loop. Each of the other phenylene groups, $B$ and $C$, is represented by an $A^{\prime} A^{\prime} B^{\prime}$ spin system, consistent with fast internal rotations. Ring $C$ produces a 
sharp $A B C D$ pattern at $200 \mathrm{~K}$ in $C D \mathrm{Cl}_{2} \mathrm{~F}$ (ee'ff'), whereas the signals of ring $B$ (cc'dd') reach the coalescence point at ca. 160-170 K. These observations clearly show that the rate of phenylene rotations for rings B-D decreases significantly with the increasing local curvature of the loop. Protons located closer to the concave surface of the loop (b', e', f', g, and h) give resonances shifted to higher field, reflecting the increased magnetic shielding inside the lemniscate.

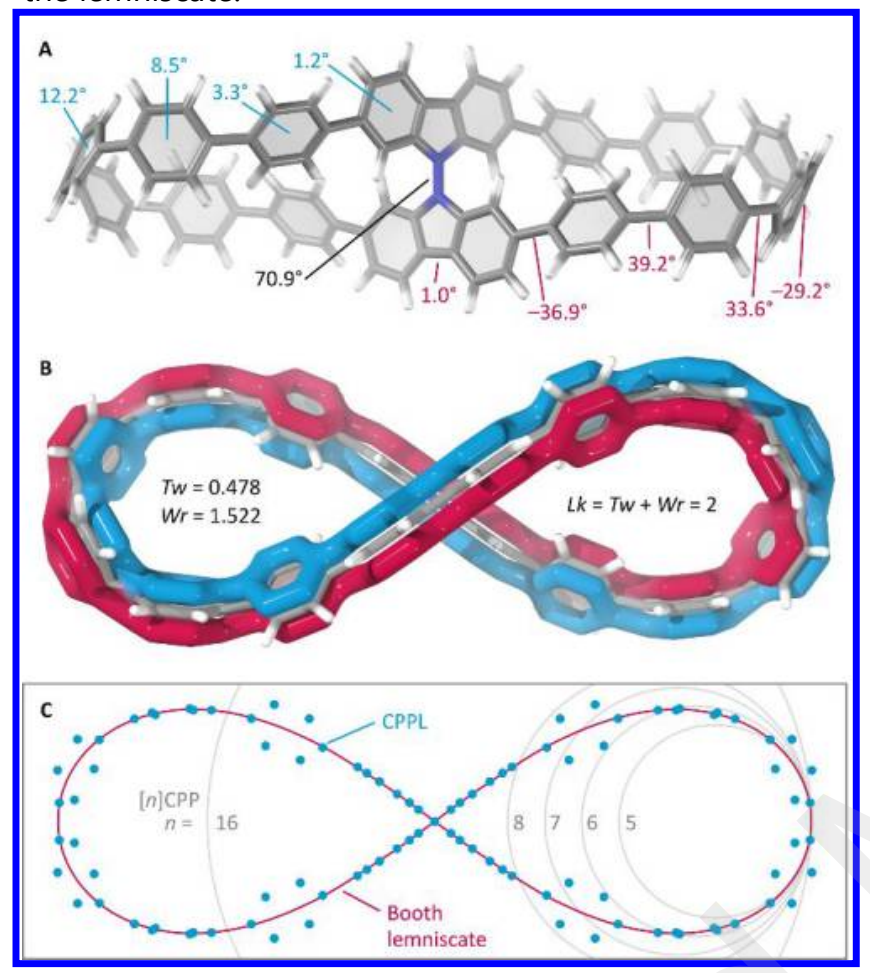

Figure 2. Lowest-energy conformation of $(P)$-1 determined in DFT calculations ( $\omega B 97 X D / 6-31 G(d, p)$, in vacuo). (A) Side view and key geometrical parameters: mean boat angles, interplanar angles, and mean CCCC torsion angles are shown in blue, black, and red, respectively. (B) Pictorial representation of the $\pi$ electron system, showing that the blue and red parts are interlocked. (C) Numerical fitting of the carbon framework of CPPL with a Booth lemniscate. Projections of several $[n]$ CPP rings are shown for comparison.

In addition to the differential decoalescence described above, some ${ }^{1} \mathrm{H}$ NMR signals of $\mathbf{1}$ revealed temperaturedependent changes of chemical shifts. These variations are relatively small (up to ca. $0.1 \mathrm{ppm}$ in the 160-220 K range in $\left(\mathrm{CDCl}_{2} \mathrm{~F}\right.$ ) and may reflect an equilibrium between several conformations that differ in the relative orientations of some phenylene rings, but are nearly degenerate energetically. In such a case, 1 would exist as a mixture of rapidly exchanging conformers even at 160 $K$, while still producing a spectrum with effective $D_{2}$ symmetry. In spite of this presumed conformational inhomogeneity, almost all of the ${ }^{13} \mathrm{C}$ NMR signals of $\mathbf{1}$ could be assigned using correlation spectroscopy $\left(\mathrm{CDCl}_{2} \mathrm{~F}\right.$, $200 \mathrm{~K}$, Supporting Information). Importantly, the corresponding chemical shifts yielded a satisfactory correlation with the theoretical GIAO shieldings. The latter result provides additional evidence in support of the proposed structure of $\mathbf{1}$.

The curvature of the cycloparaphenylene belt contained in CPPL varies along the periphery. Rings $D$ are most strongly curved, with the mean boat angle of $12.2^{\circ}$, comparable with the value of $12.7^{\circ}$ determined for [6]CPP. ${ }^{30}$ The boat angles decrease for rings $C\left(8.5^{\circ}\right)$ and $B$ $\left(3.3^{\circ}\right)$, and the carbazole units are nearly planar. The dihedral angle between carbazole planes $\left(70.9^{\circ}\right)$ is smaller than observed in the crystal structures of $\mathbf{2}\left(85.6-89.3^{\circ}\right), \mathbf{3}$ $\left(79.2^{\circ}\right)$, and $6\left(90.4^{\circ}\right.$ inside the loop, Scheme 1$)$. Nevertheless, the scissor-like compression of the bicarbazole unit is relatively small in $\mathbf{1}$. Mean torsional angles between consecutive phenylenes show alternating signs in the regions of low curvature (rings $A-B-C$ ), a typical feature found in $[n] C P P$ structures. The highcurvature regions (rings $C-D-D-C$ ) are characterized by uniform signs of phenylene torsions, corresponding to the helical shape of the loop. In spite of the significant overall twist of the macrocycle in $\mathrm{CPPL}$, the largest interphenylene torsions do not exceed $40^{\circ}$, i.e. are within the range observed experimentally for circular CPP systems. The $\pi$ surface of $\mathbf{1}$ is therefore characterized by fairly effective and contiguous overlap of $p_{z}$ orbitals along the macrocycle. Thus, CPPL and similarly designed systems can be expected to sustain macrocyclic conjugation in their charged states, in analogy to CPP nanohoops. ${ }^{11-13} \mathbf{1}$ resembles some recently reported multi-loop CPP derivatives, ${ }^{31-33}$ but it is the first such system containing a contiguous $[n]$ CPP substructure. Because of the large interplanar angle between the carbazoles, the $\pi$ system is effectively decoupled along the $\mathrm{N}-\mathrm{N}$ linkage, which thus serves only as a steric restraint necessary to support the lemniscular conformation.

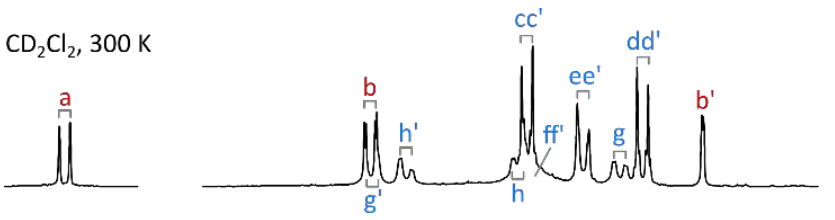

$\mathrm{CDCl}_{2} \mathrm{~F}, 200 \mathrm{~K}$

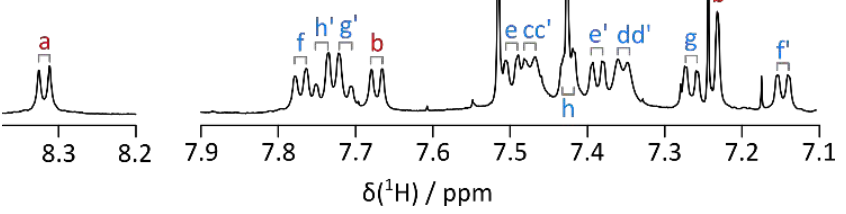

Figure 3. ${ }^{1} \mathrm{H}$ NMR spectra of $\mathbf{1}$ at two different temperatures $(600 \mathrm{MHz})$. Labeling is defined in Scheme 1. Additional NMR data are given in the Supporting Information.

The lemniscular structure of $\mathbf{1}$ is characterized by a linking number of $|L k|=2$, corresponding to a double halftwist of the $\pi$ system. ${ }^{14}$ The latter feature can be verified 
by noting that the two sides of the $\pi$ surface (red and blue in Figure $2 \mathrm{~B}$ ) are interlocked in space, forming the socalled Hopf link. ${ }^{15}$ The linking number $L k$ can be decomposed into twist $(T w)$ and writhe $(W r)$ according to the Călugăreanu formula, $L k=T w+W r{ }^{14}$ The twist parameter $T w$ was calculated for $\mathbf{1}$ as the cumulative rotation of POAV1 ${ }^{34}$ vectors along the backbone of quaternary $p$-phenylene carbons. The resulting value of $|T w|=0.478$ is lower than typically observed in figureeight aromatics with planar conjugation, 15,35 and indicates a high level of $p$-orbital overlap in the $\pi$-conjugated system. Interestingly, when the DFT structure of $\mathbf{1}$ is projected onto a plane along the $\mathrm{N}-\mathrm{N}$ bond, the network of carbon atoms can be very accurately approximated with a Booth lemniscate. ${ }^{36}$ In polar coordinates, the latter curve is defined as $r^{2}=4 b\left(a-b \sin ^{2} \theta\right)$, and the best fit for CPPL is obtained with $a=4.07 \AA$ and $b=11.57 \AA$, which correspond to a lemniscate with lateral dimensions of $27.4 \AA \times 8.1 \AA$ (Figure $2 \mathrm{C}$ ).

The solid-state Raman spectrum of $\mathbf{1}$, in combination with a theoretical normal-mode analysis (Figure 4), provides an important insight into the curvature and strain of CPPL. The CC stretching modes of the benzene rings are observed in the $1629-1576 \mathrm{~cm}^{-1}$ range. The $1576 \mathrm{~cm}^{-}$ 1 mode correlates with those determined for [6]- and [7]CPP (1567 cm $\mathrm{cm}^{-1}$ and $1574 \mathrm{~cm}^{-1}$, respectively), ${ }^{37}$ indicating that a fragment with a similar degree of quinoidal character may be present in CPPL. The highest frequency band in this rage $\left(1629 \mathrm{~cm}^{-1}\right)$ corresponds mostly to stretches in the carbazole units and agrees well with the corresponding stretch in free carbazole $\left(1625 \mathrm{~cm}^{-}\right.$ $\left.{ }^{1}\right) .{ }^{38}$ In the low wavenumber region, the experimental bands at 509 and $476 \mathrm{~cm}^{-1}$ were assigned to $\mathrm{C}-\mathrm{H}$ out-ofplane deformation vibrations. Four additional bands $\left(404.5,364,204\right.$, and $\left.169 / 159 \mathrm{~cm}^{-1}\right)$, were identified as pseudo radial breathing modes or ( $p$-RBMs), i.e. out-ofplane CCC modes with their motion amplitudes along the radial direction of the loop, analogous to those found in $[n]$ CPPs. $^{37}$ The previously established empirical dependence between the $\mathrm{p}$-RBM frequency and internal strain in CPPs produced an estimated strain energy of $122.5 \mathrm{kcal} / \mathrm{mol}$ for CPPL. A direct homodesmotic calculation, performed in analogy to a previously reported scheme, ${ }^{39}$ yielded a strain enthalpy of $\Delta H=102.7 \mathrm{kcal} / \mathrm{mol}$ for CPPL, in very good agreement with the above empirical prediction (Supporting Information).

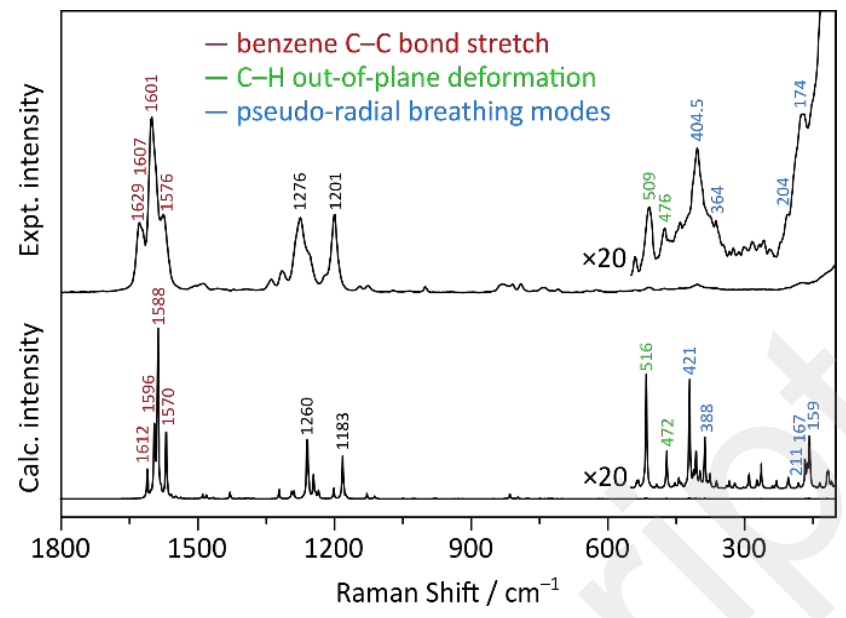

Figure 4. Comparison of the experimental FT-Raman spectrum of CPPL (top) with the DFT-predicted spectrum (B3LYP/6-31G(d), energy scaling factor 0.96 , bottom).

Electronic Structure. In dichloromethane, 1 exhibits a single absorption peak at $357 \mathrm{~nm}$ (Figure 5A, $\varepsilon=$ $\left.142000 \mathrm{M}^{-1} \mathrm{~cm}^{-1}\right)$, somewhat red-shifted in comparison with [16]CPP $(339 \mathrm{~nm}){ }^{40}$ The spectrum of $\mathbf{1}$ features a long-wavelength shoulder, which extends up to ca. 450 $\mathrm{nm}$ and is responsible for the pale-yellow color of the compound. The greenish fluorescence emission of $\mathbf{1}$ has a maximum at $496 \mathrm{~nm}$ and a quantum yield of $\Phi_{\mathrm{F}}=0.36$. A similar emission band, with a more clearly resolved vibronic structure, was observed in 2methyltetrahydrofuran at $80 \mathrm{~K}$ (Figure S2). As a fluorophore, CPPL differs markedly from the cycloparaphenylene series, with which it is structurally related. Large $[n]$ CPPs $(n>9)$ have been found to emit strongly from the $S_{2}$ state, whereas smaller nanohoops emit primarily from $S_{1}$, albeit with progressively diminishing quantum yields. ${ }^{1,30,41-44}$ The large apparent Stokes shift observed for CPPL suggests that its emission is " $\mathrm{S}_{1}$-like" in spite of the large size of the embedded nanohoop. Indeed, photoluminescence properties of $\mathbf{1}$ differ significantly from those of the parent [16]CPP $\left(\lambda_{\mathrm{em}}=\right.$ 415 and $438 \mathrm{~nm} ; \Phi_{\mathrm{F}}=0.88$ ). The position of the emission maximum is closest to that reported for [9]CPP (494 nm), which is however a stronger emitter $\left(\Phi_{\mathrm{F}}=0.73\right){ }^{1,40}$ The emission lifetime of $\mathbf{1}$ (2.92 ns) is longer than that of [16]CPP (ca. $0.9 \mathrm{~ns}$ ) and matches those of smaller CPPs ( $n$ $\sim 10-11),{ }^{45}$ reflecting the expected influence of increased curvature in CPPL on exciton dynamics. 

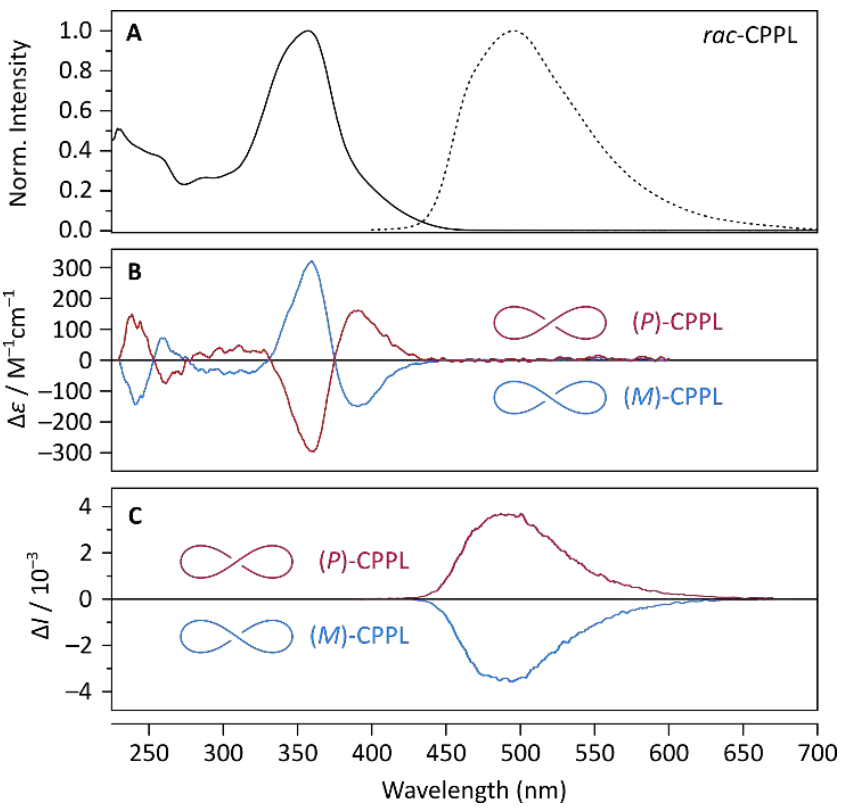

Figure 5. (A) Electronic absorption spectrum (solid line) and emission spectrum of $\mathbf{1}$ (dashed line, both in dichloromethane). (B) Electronic circular dichroism spectra of (P)-1 and (M)-1 (298 K, ca. 10-6 M in dichloromethane). (C) Circularly polarized luminescence spectra of $(P)-\mathbf{1}$ and $(M)-\mathbf{1}$ (ca. $10^{-6} \mathrm{M}$ in dichloromethane) at $298 \mathrm{~K}\left(\lambda_{\mathrm{exc}}=350 \mathrm{~nm}\right), \Delta l=$ $I_{L}-I_{R}$.

Kohn-Sham HOMO and LUMO levels of CPPL, obtained from DFT calculations, are both non-degenerate and their nodal characteristics are analogous to those of [16]CPP (Figure 6). At the B3LYP/6-31G(d) level of theory, the bandgap of CPPL is $3.35 \mathrm{eV}$, i.e. it is smaller than the calculated gap of [16]CPP (3.66 eV). In comparison, the dicarbazole nanohoop $\mathbf{1}-\mathrm{H}_{2}$, which is structurally intermediate between [16]CPP and CPPL, is predicted to have an energy gap essentially identical with that of its CPP parent. In both $\mathbf{1}$ and $\mathbf{1}-\mathrm{H}_{2}, \mathrm{HOMO}$ and LUMO amplitudes at the nitrogen atoms are small, indicating that the perturbation of frontier energy levels caused by the heteroatoms is insignificant. Thus, since the conjugation length is identical in [16]CPP and CPPL, the reduced optical bandgap of the latter species can be mostly attributed to its higher curvature. The lower symmetry of CPPL $\left(D_{2}\right)$ in comparison with the circular CPPs results in a more complex pattern of electronic transitions, as determined in time-dependent (TD) DFT calculations (Figure 6). The lowest-energy transition of $\mathbf{1}$ is dominated by the HOMO-LUMO excitation and is weakly allowed $(f=0.03)$. It is followed by three other weak transitions $\left(S_{2}-S_{4}, f=0.01-0.10\right)$, and a very strong one $\left(S_{5}, f=3.56\right)$. This pattern differs from the spectra of [n]CPPs, which feature a dipole-forbidden $\mathrm{S}_{1}$ transition, followed directly by the very strong $S_{2}$. The partially allowed character of the lowest excited states may contribute the relatively strong $\mathrm{S}_{1}$-type fluorescence emission of $\mathbf{1}$, which is more typical of smaller CPP rings $(n<10)$.

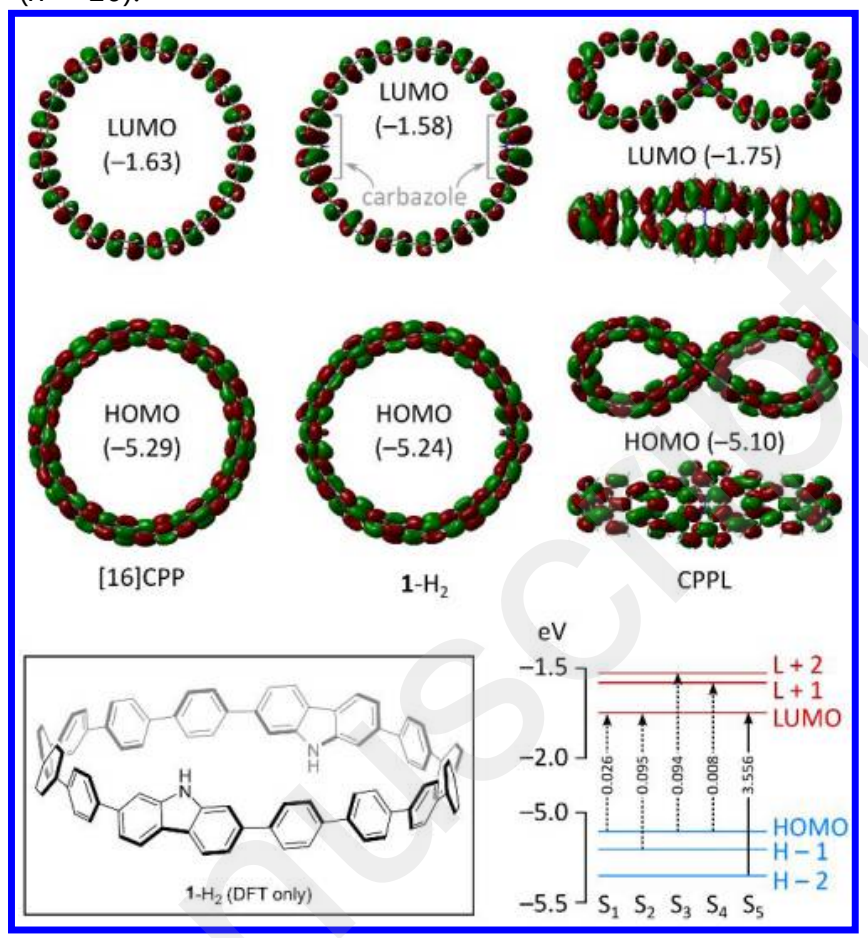

Figure 6. Top: Kohn-Sham HOMO and LUMO orbitals for CPPL and its analogues (0.01 a.u. isosurfaces, energies in eV). Bottom right: lowest energy electronic transitions determined using time-dependent DFT. Arrows indicate principal excitations. Dotted arrows correspond to $f<0.10$. All calculations were performed at the B3LYP/6-31G(d) level of theory.

The first oxidation of $\mathbf{1}$ observed in dichloromethane using voltammetric methods has limited chemical reversibility (Supporting Information). The oxidation potential of $0.64 \mathrm{~V} \mathrm{vs}$. $\mathrm{Fc} / \mathrm{Fc}^{+}$is substantially lower than the values reported for large CPPs (ca. $0.9 \mathrm{~V}){ }_{1}^{46}$ and correlates with the shift of the HOMO level discussed above. The first reduction of $\mathbf{1}$ was observed at $-2.36 \mathrm{~V}$, yielding an electrochemical gap of $3.00 \mathrm{eV}$, in good agreement with the gaps derived from optical absorption and TD-DFT.

Since a 64-electron macrocyclic circuit can formally be distinguished in the structure of $\mathbf{1}$, the molecule might in principle be expected to exhibit Hückel-antiaromatic ( $4 n$ electron) characteristics. However, the purely benzenoid framework of $\mathrm{CPPL}$, which is not cross-conjugated with the central $\mathrm{N}-\mathrm{N}$ unit, produces a conjugation pattern that is accurately described in terms of 16 Clar sextets, in analogy to other cycloparaphenylene systems. Such a formulation is reflected in the magnetic properties of $\mathbf{1}$ determined using ${ }^{1} \mathrm{H}$ NMR, and also in the computationally modeled bond length patterns, obtained at various levels of theory (Supporting Information), which show that $\pi$ bond delocalization is confined to sixmembered rings. Quinoidal features, caused by curvature 
of individual benzene units, can nevertheless be traced in the Raman spectra of $\mathbf{1}$, as discussed above.

Chirality. CPPL is a chiral molecule, in which the twisted 9,9'-bicarbazole unit acts as the stereogenic element. CPPL is thus different from other chiral CPP-related systems, in which enantiomer differentiation was achieved via locked internal rotation of desymmetrized aromatic subunits, ${ }^{47,48}$ or by introduction of $\mathrm{sp}^{3}$ stereocenters. ${ }^{33}$ The oligophenylene loops in $\mathbf{1}$ are apparently not essential for configurational stability, as suggested by the atropisomerism of the naturally occurring dixiamycins $A$ and $B$, which also contain the 9,9'-bicarbazole moiety. ${ }^{49}$ Enantiomers of $\mathbf{1}$ were precisely resolved by means of supercritical fluid chromatography on a chiral stationary phase. According to the convention previously adopted for figure-eight aromatics, ${ }^{50}$ the enantiomer of CPPL shown in Scheme 1 and Figure 2 is labeled $(P)$-1, to reflect the local helicity of the constituent oligophenylene loops. At room temperature, the enantiomers of $\mathbf{1}$ do not racemize in solution, but their stability upon heating could not be reliably verified because of gradual decomposition. According to DFT calculations, inversion of the lemniscate should occur via a $C_{s}$-symmetrical transition state with a predicted in-vacuo barrier of $\Delta G^{\ddagger}, 298=51.4 \mathrm{kcal} / \mathrm{mol}$. This high value implies that enantiomers of $\mathbf{1}$ should be configurationally stable even at elevated temperatures.

The figure-eight shape of the CPPL chromophore makes it of interest as a chiroptical material. ${ }^{50,51}$ The electronic circular dichroism (ECD) spectra of pure CPPL enantiomers each contain two major Cotton effects of opposite signs (Figure $5 \mathrm{~B})$. The more intense peak $\left(\Delta \varepsilon \approx 300 \mathrm{M}^{-1} \mathrm{~cm}^{-1}\right)$ is found at $360 \mathrm{~nm}$, whereas the other is located at $390 \mathrm{~nm}$ and approximately coincides with the shoulder observed in the absorption spectrum. An additional weaker Cotton effect is found at ca. $250 \mathrm{~nm}\left(\Delta \varepsilon \approx 100 \mathrm{M}^{-1} \mathrm{~cm}^{-1}\right)$. The absolute configuration of $P$ and $M$ enantiomers of $\mathbf{1}$, indicated in Figure 5B, was established on the basis of TDDFT calculations employing B3LYP and CAM-B3LYP52 functionals (Supporting Information). In particular, in the CD spectrum calculated using B3LYP/6-31G(d), the highest rotatory strengths corresponded to the $S_{5}$ and $S_{2}$ transitions. The two enantiomers yielded mirror-image circularly polarized luminescence (CPL) spectra with dissymmetry factors $\left|g_{\text {lum }}\right|$ of around $3.7 \cdot 10^{-3}$ at $498 \mathrm{~nm}$, i.e. in the range typically observed for organic CPL emitters $^{53,54}$ (Figure 5C). Interestingly, this $g_{\text {lum }}$ value is close to the dissymmetry factor $g_{\text {abs }}$ observed in the ECD spectra $\left(\left|g_{\mathrm{abs}}\right|=4 \cdot 10^{-3}\right.$ at $\left.400 \mathrm{~nm}\right)$, suggesting that both the ground state and the emitting excited state of $\mathbf{1}$ have similar chiral geometries.

\section{CONCLUSIONS}

CPPL, the lemniscular analogue of [16]cycloparaphenylene described in this work is the first example of a radially conjugated $\pi$-electron system with a double half-twist. The structural design of CPPL provides a unique opportunity to observe the effect of curvature variations on the electronic structure in isolation from other influences. The electronic properties of this new system differ from those of the parent [16]CPP ring, showing absorption and emission features more characteristic of smaller cycloparaphenylenes. The twisted nanohoop of CPPL can be resolved into configurationally stable enantiomers, which are found to produce circularly polarized luminescence. More generally, the approach to curvature control presented herein enables reduction of electronic bandgaps while retaining large conjugation lengths in nanohoop systems. Additionally, by creating small loops with chiral interiors the new design is of interest for its potential use in supramolecular chemistry. ${ }^{55,56}$ Efforts to explore these new possibilities are currently underway in our laboratories.

\section{ASSOCIATED CONTENT}

\section{Supporting Information}

Synthetic and spectroscopic details, computational data. The Supporting Information is available free of charge on the ACS Publications website.

\section{AUTHOR INFORMATION}

\section{Corresponding Author}

marcin.stepien@chem.uni.wroc.pl

casado@uma.es

\section{ACKNOWLEDGMENT}

Financial support from the National Science Center of Poland (DEC-2015/19/B/ST5/00612, M.S.) is gratefully acknowledged. Quantum-chemical calculations were performed in the Wrocław Center for Networking and Supercomputing. J.C. (Málaga) thanks MINECO/FEDER of the Spanish Government (project reference CTQ2015-69391-P) and the Research Central Services (SCAI) of the University of Málaga. J.C. (Rennes) and L.F. thank the Ministère de I'Education Nationale, de la Recherche et de la Technologie, the Centre National de la Recherche Scientifique (CNRS), and Rennes Métropole for financial support. T.V. and the ENSCR thank the Shimadzu and Chiral Technology companies for their support regarding the separation of chiral molecules by supercritical fluid chromatography (SFC).

\section{REFERENCES}

(1) Jasti, R.; Bhattacharjee, J.; Neaton, J. B.; Bertozzi, C. R. Synthesis, Characterization, and Theory of [9]-, [12]-, and [18]Cycloparaphenylene: Carbon Nanohoop Structures. J. Am. Chem. Soc. 2008, 130 (52), 17646-17647.

(2) Yamago, S.; Kayahara, E.; Iwamoto, T. OrganoplatinumMediated Synthesis of Cyclic $\pi$-Conjugated Molecules: Towards 
a New Era of Three-Dimensional Aromatic Compounds. Chem. Rec. 2014, 14 (1), 84-100.

(3) Golder, M. R.; Jasti, R. Syntheses of the Smallest Carbon Nanohoops and the Emergence of Unique Physical Phenomena. Acc. Chem. Res. 2015, 48 (3), 557-566.

(4) Lewis, S. E. Cycloparaphenylenes and Related Nanohoops. Chem. Soc. Rev. 2015, 44 (8), 2221-2304.

(5) Segawa, Y.; Ito, H.; Itami, K. Structurally Uniform and Atomically Precise Carbon Nanostructures. Nat. Rev. Mater. 2016 $1,15002$.

(6) Povie, G.; Segawa, Y.; Nishihara, T.; Miyauchi, Y.; Itami, K. Synthesis of a Carbon Nanobelt. Science 2017, 356 (6334), $172-175$

(7) Sun, Z.; Ikemoto, K.; Fukunaga, T. M.; Koretsune, T.; Arita, R.; Sato, S.; Isobe, H. Finite Phenine Nanotubes with Periodic Vacancy Defects. Science 2019, 363 (6423), 151-155.

(8) Scott, L. T.; Jackson, E. A.; Zhang, Q.; Steinberg, B. D.; Bancu, M.; Li, B. A Short, Rigid, Structurally Pure Carbon Nanotube by Stepwise Chemical Synthesis. J. Am. Chem. Soc. 2012, 134 (1), 107-110.

(9) Myśliwiec, D.; Kondratowicz, M.; Lis, T.; Chmielewski, P. J.; Stępień, M. Highly Strained Nonclassical Nanotube End-Caps. A Single-Step Solution Synthesis from Strain-Free, NonMacrocyclic Precursors. J. Am. Chem. Soc. 2015, 137 (4), 16431649.

(10) Heilbronner, E. Hückel Molecular Orbitals of MöbiusType Conformations of Annulenes. Tetrahedron Lett. 1964, 5 (29), 1923-1928.

(11) Kayahara, E.; Kouyama, T.; Kato, T.; Takaya, H.; Yasuda, $\mathrm{N}$.; Yamago, S. Isolation and Characterization of the Cycloparaphenylene Radical Cation and Dication. Angew. Chem. Int. Ed. 2013, 52 (51), 13722-13726.

(12) Toriumi, N.; Muranaka, A.; Kayahara, E.; Yamago, S.; Uchiyama, M. In-Plane Aromaticity in Cycloparaphenylene Dications: A Magnetic Circular Dichroism and Theoretical Study. J. Am. Chem. Soc. 2015, 137 (1), 82-85.

(13) Alvarez, M. P.; Delgado, M. C. R.; Taravillo, M.; Baonza V. G.; Navarrete, J. T. L.; Evans, P.; Jasti, R.; Yamago, S.; Kertesz, M.; Casado, J. The Raman Fingerprint of Cyclic Conjugation: The Case of the Stabilization of Cations and Dications in Cycloparaphenylenes. Chem. Sci. 2016, 7 (6), 3494-3499.

(14) Rappaport, S. M.; Rzepa, H. S. Intrinsically Chiral Aromaticity. Rules Incorporating Linking Number, Twist, and Writhe for Higher-Twist Möbius Annulenes. J. Am. Chem. Soc. 2008, 130 (24), 7613-7619.

(15) Stępień, M.; Sprutta, N.; Latos-Grażyński, L. Figure Eights, Möbius Bands, and More: Conformation and Aromaticity of Porphyrinoids. Angew. Chem. Int. Ed. 2011, 50 (19), 4288-4340.

(16) R. Schaller, G.; Herges, R. Möbius Molecules with Twists and Writhes. Chem. Commun. 2013, 49 (13), 1254-1260.

(17) Herges, R. Topology in Chemistry: Designing Möbius Molecules. Chem. Rev. 2006, 106 (12), 4820-4842.

(18) Tanaka, T.; Osuka, A. Chemistry of Meso -ArylSubstituted Expanded Porphyrins: Aromaticity and Molecular Twist. Chem. Rev. 2017, 117 (4), 2584-2640.

(19) Ajami, D.; Oeckler, O.; Simon, A.; Herges, R. Synthesis of a Möbius Aromatic Hydrocarbon. Nature 2003, 426 (6968), 819821.

(20) Ajami, D.; Hess, K.; Köhler, F.; Näther, C.; Oeckler, O.; Simon, A.; Yamamoto, C.; Okamoto, Y.; Herges, R. Synthesis and
Properties of the First Möbius Annulenes. Chem. - Eur. J. 2006, 12 (21), 5434-5445.

(21) Stępień, M.; Latos-Grażyński, L.; Sprutta, N.; Chwalisz, P.; Szterenberg, L. Expanded Porphyrin with a Split Personality: A Hückel-Möbius Aromaticity Switch. Angew. Chem. Int. Ed. 2007, 46 (41), 7869-7873.

(22) Tanaka, Y.; Saito, S.; Mori, S.; Aratani, N.; Shinokubo, H.; Shibata, N.; Higuchi, Y.; Yoon, Z. S.; Kim, K. S.; Noh, S. B.; Park, J. K.; Kim, D.; Osuka, A. Metalation of Expanded Porphyrins: A Chemical Trigger Used To Produce Molecular Twisting and Möbius Aromaticity. Angew. Chem. Int. Ed. 2008, 47 (4), 681-684.

(23) Schaller, G. R.; Topić, F.; Rissanen, K.; Okamoto, Y.; Shen, J.; Herges, R. Design and Synthesis of the First Triply Twisted Möbius Annulene. Nat. Chem. 2014, 6 (7), 608-613.

(24) Naulet, G.; Sturm, L.; Robert, A.; Dechambenoit, P.; Röhricht, F.; Herges, R.; Bock, H.; Durola, F. Cyclic Tris[5] Helicenes with Single and Triple Twisted Möbius Topologies and Möbius Aromaticity. Chem. Sci. 2018.

(25) Thulin, B.; Wennerström, O. Propellicene or Bi-2,13Pentahelicenylene. Acta Chem. Scand. 1976, 30b, 688-690.

(26) Robert, A.; Dechambenoit, P.; Hillard, E. A.; Bock, H.; Durola, F. Non-Planar Oligoarylene Macrocycles from Biphenyl. Chem. Commun. 2017, 53 (84), 11540-11543.

(27) Majewski, M. A.; Stępień, M. Bowls, Hoops, and Saddles: Synthetic Approaches to Curved Aromatic Molecules. Anaew. Chem. Int. Ed. 2019, 58 (1), 86-116.

(28) Kuroda, Y.; Sakamoto, Y.; Suzuki, T.; Kayahara, E.; Yamago, S. Tetracyclo(2,7-Carbazole)s: Diatropicity and Paratropicity of Inner Regions of Nanohoops. J. Ora. Chem. 2016, 81 (8), 3356-3363.

(29) Patel, V. K.; Kayahara, E.; Yamago, S. Practical Synthesis of $[n]$ Cycloparaphenylenes $(n=5,7-12)$ by $\mathrm{H}_{2} \mathrm{SnCl}_{4}$-Mediated Aromatization of 1,4-Dihydroxycyclo-2,5-Diene Precursors. Chem. - Eur. J. 2015, 21, 5742-5749.

(30) Xia, J.; Jasti, R. Synthesis, Characterization, and Crystal Structure of [6]Cycloparaphenylene. Angew. Chem. Int. Ed. 2012, 51 (10), 2474-2476.

(31) Huang, Z.-A.; Chen, C.; Yang, X.-D.; Fan, X.-B.; Zhou, W.; Tung, C.-H.; Wu, L.-Z.; Cong, H. Synthesis of OligoparaphenyleneDerived Nanohoops Employing an Anthracene Photodimerization-Cycloreversion Strategy. J. Am. Chem. Soc. 2016, 138 (35), 11144-11147.

(32) Li, P.; Zakharov, L. N.; Jasti, R. A Molecular Propeller with Three Nanohoop Blades: Synthesis, Characterization, and SolidState Packing. Angew. Chem. Int. Ed. 2017, 56 (19), 5237-5241.

(33) Xu, W.; Yang, X.-D.; Fan, X.-B.; Wang, X.; Tung, C.-H.; Wu, L.-Z.; Cong, H. Synthesis and Characterization of a PentiptyceneDerived Dual Oligoparaphenylene Nanohoop. Angew. Chem. Int. Ed. 2019, 58 (12), 3943-3947.

(34) Haddon, R. C.; Scott, L. T. $\pi$-Orbital Conjugation and Rehybridization in Bridged Annulenes and Deformed Molecules in General: $\pi$-Orbital Axis Vector Analysis. Pure Appl. Chem. 1986, 58 (1), 137-142.

(35) Rzepa, H. S. Lemniscular Hexaphyrins as Examples of Aromatic and Antiaromatic Double-Twist Möbius Molecules. Orq. Lett. 2008, 10 (5), 949-952.

(36) Lawrence, J. D. A Catalog of Special Plane Curves, First Edition edition.; Dover Publications: New York, 2014.

(37) Alvarez, M. P.; Burrezo, P. M.; Kertesz, M.; Iwamoto, T.; Yamago, S.; Xia, J.; Jasti, R.; Navarrete, J. T. L.; Taravillo, M.; Baonza, V. G.; Casado, J. Properties of Sizeable [n] Cycloparaphenylenes as 
Molecular Models of Single-Wall Carbon Nanotubes Elucidated by Raman Spectroscopy: Structural and Electron-Transfer Responses under Mechanical Stress. Angew. Chem. Int. Ed. 2014 53 (27), 7033-7037.

(38) Lee, S. Y.; Boo, B. H. Molecular Structures and Vibrational Spectra of Pyrrole and Carbazole by Density Functional Theory and Conventional Ab Initio Calculations. J. Phys. Chem. 1996, 100 (37), 15073-15078.

(39) Segawa, Y.; Omachi, H.; Itami, K. Theoretical Studies on the Structures and Strain Energies of Cycloparaphenylenes. Org. Lett. 2010, 12 (10), 2262-2265.

(40) Segawa, Y.; Fukazawa, A.; Matsuura, S.; Omachi, H.; Yamaguchi, S.; Irle, S.; Itami, K. Combined Experimental and Theoretical Studies on the Photophysical Properties of Cycloparaphenylenes. Ora. Biomol. Chem. 2012, 10 (30), 59795984.

(41) Yamago, S.; Watanabe, Y.; Iwamoto, T. Synthesis of [8]Cycloparaphenylene from a Square-Shaped Tetranuclear Platinum Complex. Angew. Chem. Int. Ed. 2010, 49 (4), 757-759.

(42) Sisto, T. J.; Golder, M. R.; Hirst, E. S.; Jasti, R. Selective Synthesis of Strained [7]Cycloparaphenylene: An OrangeEmitting Fluorophore. J. Am. Chem. Soc. 2011, 133 (40), 1580015802.

(43) Evans, P. J.; Darzi, E. R.; Jasti, R. Efficient RoomTemperature Synthesis of a Highly Strained Carbon Nanohoop Fragment of Buckminsterfullerene. Nat. Chem. 2014, 6 (5), 404 408.

(44) Kayahara, E.; Patel, V. K.; Yamago, S. Synthesis and Characterization of [5]Cycloparaphenylene. J. Am. Chem. Soc. 2014, 136 (6), 2284-2287.

(45) Nishihara, T.; Segawa, Y.; Itami, K.; Kanemitsu, Y. Exciton Recombination Dynamics in Nanoring Cycloparaphenylenes. Chem. Sci. 2014, 5 (6), 2293.

(46) Kayahara, E.; Fukayama, K.; Nishinaga, T.; Yamago, S. Size Dependence of [ $n$ ]Cycloparaphenylenes $(n=5-12)$ in Electrochemical Oxidation. Chem. - Asian J. 2016, 11 (12), 17931797.

(47) Hitosugi, S.; Nakanishi, W.; Yamasaki, T.; Isobe, H. Bottom-up Synthesis of Finite Models of Helical $(n, m)$-SingleWall Carbon Nanotubes. Nat. Commun. 2011, 2 (1).
(48) Sato, S.; Yoshii, A.; Takahashi, S.; Furumi, S.; Takeuchi, M.; Isobe, H. Chiral Intertwined Spirals and Magnetic Transition Dipole Moments Dictated by Cylinder Helicity. Proc. Natl. Acad. Sci. 2017, 114 (50), 13097-13101.

(49) Zhang, Q.; Mándi, A.; Li, S.; Chen, Y.; Zhang, W.; Tian, X.; Zhang, H.; Li, H.; Zhang, W.; Zhang, S.; Ju, J.; Kurtán, T.; Zhang, C. $\mathrm{N}-\mathrm{N}$-Coupled Indolo-Sesquiterpene Atropo-Diastereomers from a Marine-Derived Actinomycete. Eur. J. Ora. Chem. 2012, 2012 (27), 5256-5262.

(50) Werner, A.; Michels, M.; Zander, L.; Lex, J.; Vogel, E. "Figure Eight" Cyclooctapyrroles: Enantiomeric Separation and Determination of the Absolute Configuration of a Binuclear Metal Complex. Angew. Chem. Int. Ed. 1999, 38 (24), 3650-3653.

(51) Rzepa, H. S. The Chiro-Optical Properties of a Lemniscular Octaphyrin. Org. Lett. 2009, 11 (14).

(52) Yanai, T.; Tew, D. P.; Handy, N. C. A New Hybrid Exchange-Correlation Functional Using the CoulombAttenuating Method (CAM-B3LYP). Chem. Phys. Lett. 2004, 393 (1-3), 51-57.

(53) Sánchez-Carnerero, E. M.; Agarrabeitia, A. R.; Moreno, F.; Maroto, B. L.; Muller, G.; Ortiz, M. J.; de la Moya, S. Circularly Polarized Luminescence from Simple Organic Molecules. Chem. - Eur. J. 2015, 21 (39), 13488-13500.

(54) Tanaka, H.; Inoue, Y.; Mori, T. Circularly Polarized Luminescence and Circular Dichroisms in Small Organic Molecules: Correlation between Excitation and Emission Dissymmetry Factors. ChemPhotoChem 2018, 2 (5), 386-402.

(55) Fan, Y.-Y.; Chen, D.; Huang, Z.-A.; Zhu, J.; Tung, C.-H.; $\mathrm{Wu}$, L.-Z.; Cong, H. An Isolable Catenane Consisting of Two Möbius Conjugated Nanohoops. Nat. Commun. 2018, 9 (1), 3037.

(56) Xu, Y.; Kaur, R.; Wang, B.; Minameyer, M. B.; Gsänger, S.; Meyer, B.; Drewello, T.; Guldi, D. M.; von Delius, M. ConcaveConvex $\pi-\pi$ Template Approach Enables the Synthesis of [10]Cycloparaphenylene-Fullerene [2]Rotaxanes. J. Am. Chem. Soc. 2018, 140 (41), 13413-13420. 


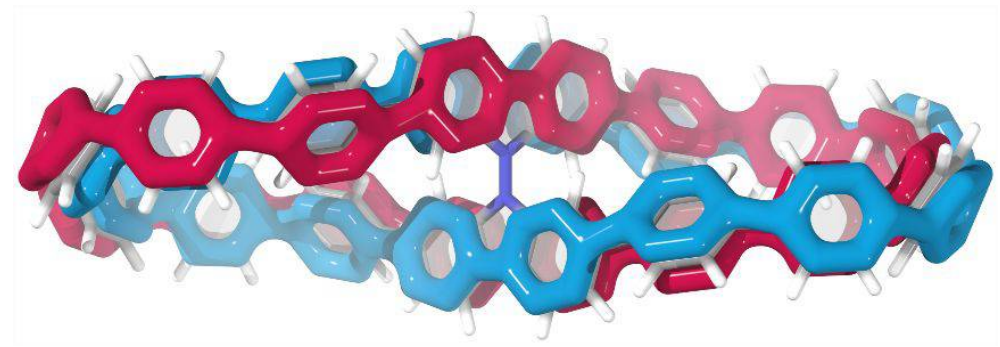

